\title{
ТOM \\ Observing and drawing the Sun: research-based insights to assess science communication practices aimed at children
}

\section{Sara Anjos, Alexandre Aibéo and Anabela Carvalho}

\begin{abstract}
Knowing how specific publics understand and experience science is crucial for both researchers and practitioners. As learning and meaning-making develop over time, depending on a combination of factors, creative possibilities to analyze those processes are needed to improve evaluation of science communication practices.

We examine how first grade children's drawings expressed their perceptions of the Sun and explore their views of a major astronomical body within their social, cultural and personal worlds. We then examine how the observation of the Sun through a telescope led to changes in graphical representations, and how learning and meaning evolved after several months.
\end{abstract}

Keywords

DOI

Introduction
Informal learning; Representations of science and technology; Visual communication

https://doi.org/10.22323/2.18040203

Submitted: 4th October 2018

Accepted: 3rd June 2019

Published: 15th July 2019

Astronomy is widely viewed as a broadly inspiring subject area (for boys and girls alike) and a gateway to diverse scientific areas [Rosenberg et al., 2014; Sjøberg and Schreiner, 2010]. It is one of the oldest sciences, providing connections to other fields of knowledge, such as Mathematics, Philosophy and History, among others, in a holistic manner. Observing the sky is both an ancient practice of humankind [Baity et al., 1973] and an early and natural exercise in childhood [Villarroel and Villanueva, 2017]. These are some of the reasons why astronomy is often deemed an attractive domain for science communication and science education activities aimed at increasing science literacy.

Although there is already a considerable amount of research about the topics of astronomy and representations of astronomy in school curricula and in museums [e.g. Lelliott and Rollnick, 2010], little is known about the conceptions that the youngest have of celestial objects, such as the Sun, when entering the educational 
system and the implications this may have for the acquisition of literacy, specifically science literacy. In part, this is due to the difficulty in using some types of evaluation tools with such young audiences; written surveys, for instance, require that respondents already have a considerable proficiency in reading and writing. Although we have found some attempts at alternatives described in the literature, we note that most of the evaluation practices that are employed are quite mediated, making it difficult for the most "primitive" conceptions of the younger to emerge in a natural way. This study seeks to make some contributions in this regard.

Given the importance of evaluation for reflecting on and informing science communication practices, it should be turned into a common exercise in various settings. One of its key challenges is to understand the changes that a science communication activity may produce on specific publics' perceptions of a scientific phenomenon and of science itself [Rennie, 2001; Koolstra, 2008; Neresini and Pellegrini, 2008; Price and Lee, 2013]. Evaluating changes produced in an individual is a very defying task as the single fact of knowing that one is being evaluated affects the result [Neresini and Pellegrini, 2008]. Therefore it is important to conceive assessment practices that are robust, fruitful and appropriate for specific audiences, for instance, by being centered on children. Several authors attest that through drawings children communicate their knowledge and experiences, this being their preferred mode of representation and meaning-making, which sets the basis for the development of other forms of literacy [Cox, 2005; Kendrick and Mckay, 2004; Kress, 2003; Mitchell, 2006; Wright, 2007].

This paper offers novel insights on children's perspectives regarding scientific observations in the context of a science communication activity conducted at school. In looking for indicators to evaluate impact, we explore children's drawings of an astronomical body, the Sun, before and after observing it through a telescope. The following research questions guided this project: what are the dominant traits of children's everyday drawings of the Sun? How will children change their drawings further to the observation of the Sun through a telescope, if at all? What can we infer from those changes about the impact of science communication practices?

We organized an observation of the Sun via a telescope equipped with a proper filter for first-grade children and developed a three-moment evaluation design of their graphical representations of the Sun: before the observation, afterwards and long after, providing a follow up to findings from the second moment. From the children's perspective, the free drawing activities had no evaluative intention. The present paper describes how such activities were implemented and offers an analysis of the three moments of evaluation as well as a comparison between them. We aim to contribute to promoting a discussion of forms of evaluation and to setting the grounds for the development of new, more effective, feedback-based practices in science communication. ${ }^{1}$

\footnotetext{
${ }^{1}$ A preliminary version of this study was presented at the '11th International Conference on Hands-on Science' held in Aveiro, Portugal, July 21-25, 2014, and appeared in its proceedings: Costa, M.F.M., Pombo, P., and Dorrío, B.V. (Eds.) Hands-on science: science education with and for society. Hands-on Science Network. Braga: Copissáurio.
} 
Theoretical backgrounds
This study was inspired by various bodies of scholarship, namely on science literacy, on evaluation of science communication activities and on children's drawings. Below we briefly discuss key issues within each of these research domains.

\section{Science literacy and engagement with science}

Advances in science (e.g. in bioengineering or in knowledge about the universe and our place in it) affect our individual and collective existence and are likely to shape ethical choices, law, economics and politics. Hence, debates on (the implications of) science will require informed consideration by citizens and a willingness to communicate in a lucid and conscious way from scientists [Steiner and Vilar, 2008].

The development of scientific literacy is widely viewed as critical to societies as it may help citizens understand the world around them; engage in debates about science; question the claims of others about scientific matters; identify key issues, search for information and draw conclusions in order to make informed decisions, inter alia, about the environment, their own health and own welfare [Hackling, Goodrum and Rennie, 2001]. Miller and Pardo [2000] have maintained that civic scientific literacy involves three different dimensions: content (knowledge of a basic science-related vocabulary that allows for understanding articles in mainstream newspapers and magazines, for example); process (the understanding of the essence of the scientific method); and social factors (recognition of science and technology's effects for individuals and societies). Subsequent analyses of scientific literacy have taken into account aspects related to contexts, skills, and ways of thinking and acting towards science, developing a holistic definition of the concept. Scientific literacy is, therefore, the ideal situation in which people are aware of science, interested, involved, and capable of forming opinions and making decisions [e.g. Burns, O'Connor and Stocklmayer, 2003].

For the Committee on Science Literacy and Public Perception of Science [2016], science literacy comprises foundational literacies as a basic level, which include numeracy, textual literacy, visual literacy, and understanding of graphs and charts among others. In this sense, science literacy is multidimensional as it involves "language, physical gestures, mathematical symbols, and visual adjuncts" [Yore, Bisanz and Hand, 2003, p. 716] and is related to other fields of study [Hand, Lawrence and Yore, 1999]. The increasing use of images (drawings, diagrams, photographs, film) in science practices and in science communication processes reinforces the importance of the visual component in science literacy [Bucchi and Saracino, 2016; Kress, 2003], namely for assessment practices.

It is well known that there are several misconceptions related to scientific facts among various publics [e.g. Dunlop, 2000; Lelliott and Rollnick, 2010; Stocklmayer, Gore and Bryant, 2001]. This is particularly the case with astronomical facts because they are sometimes counter-intuitive. Understanding when and how those misconceptions originate can be useful to rethink science education and communication practices for younger people, especially as it is known that some of these misconceptions are persistent throughout life.

Cultivating scientific literacy should be an important focus of education in early school years. 
Although high levels of universal scientific literacy are still an intangible ideal, it remains a crucial goal for modern societies through formal, non-formal or informal learning. ${ }^{2}$ Regardless of the importance of formal schooling for enhancing science literacy among young children, they form their first impressions of scientific phenomena at early ages, and most likely those perceptions affect their attitudes and learning [Buldu, 2006]. Hence, we must reflect on the impact of numerous means and practices of communication, such as those involved in children's literature (including text and illustrations), in television programmes for children and, more generally, in cultural icons, symbols and stereotypes. Understanding how children's views of the world relate to those various aspects is crucial to identify potential impacts of science communication practices.

Science communication activities are often complementary of formal education practices. For professionals and others involved in those activities, evaluating their effectiveness is hugely important to inform practice. Hence, a continuing search for proper evaluation methods for each situation and each practice is in order [Grand and Sardo, 2017; Jensen, 2015].

\section{Evaluating science communication activities}

The growing offer of science communication activities and the number of interested stakeholders bring added challenges to evaluation processes [Grand and Sardo, 2017]. Evaluation aims to examine the effect produced by a given action, by taking into account the purpose for which such action was designed and built [Neresini and Pellegrini, 2008]. There are many social actors involved in science communication (scientists, mediators, policy makers, entrepreneurs, students, general public, etc.), each pursuing distinct objectives and often assigning different meanings to terms used to formulate certain objectives. Each actor observes and evaluates the process and the results from different points of view [Neresini and Pellegrini, 2008; Grand and Sardo, 2017]. In order to develop a common perspective (at least partially), it is important to establish some reference parameters based on the choices of those involved and from negotiation between them [Jensen, 2015; Neresini and Pellegrini, 2008]. This means that evaluation produces results are only valid within a specific context.

Thus, evaluating science communication initiatives depends on the context of their implementation, on the definition and negotiation of goals, and on the type of activity developed to achieve them. The relation between the design of a given communication activity and its evaluation is important and should be thoroughly considered. Another relevant issue concerns the choice between quantitative and/or qualitative methods. A multi-method approach [Rowe and Frewer, 2005] is generally considered a good strategy for improving the effectiveness of the assessment.

\footnotetext{
${ }^{2}$ The distinction between formal, non-formal and informal learning can be summarized as follows: - formal learning is what takes place in a structured and organized context, is developed in educational and training institutions, and usually results in formal recognition (diploma or certificate); - non-formal learning occurs through planned activities that are not explicitly oriented to learning but that have a learning component (for instance, in the community, in associations, in recreational and leisure settings, etc.); - informal learning results from broader life situations, and is often not recognized (individually and socially) [Bjornavold, 2000]. Some authors believe that the difference between non-formal and informal learning is rather vague and therefore frequently only one of such terms is employed.
} 
Evaluation of science communication activities aims to assess changes that can take place at three levels: at the knowledge level (which relates to learning); in attitudes (which concern how to make judgements and forge opinions); and at the level of behaviour (i.e. acting differently from before) [Neresini and Pellegrini, 2008]. Hence, the central problem in assessing becomes the observation of change. As with experiments in a laboratory, in conducting such an observation, the ex-ante situation is compared with the ex-post situation (ibid.). To that purpose, a group of subjects is involved in the communication process that the researcher is focusing on while another group (the control group) is not. It is then assumed that the observed changes are due to the said communication process. It is clear that such comparison fails in certain respects, as in much research in social sciences, because it is impossible to obtain two identical or sufficiently similar groups, thus violating the principle of experimental investigation. Moreover, if the group involved knows beforehand that they are being evaluated, either by completing a questionnaire or being interviewed (activities which, by themselves, are also communication processes), this will confound the origin of the change that one may observe.

Various approaches have been tested in order to find ways around these challenges [Pidgeon et al., 2005; Rowe and Frewer, 2004]. One proposes ex-post observation only, with the researcher examining certain elements after the completion of a science communication activity and interpreting them as indicators of change produced by that process. In this case, the target public develops a self-evaluation of the activity through questionnaires and in-depth interviews and the data is then analysed by the researcher.

Time is one (more) important factor to consider. Several time-related assumptions and limitations in evaluation can be problematic. Both practitioners and researchers often expect major changes in learning, attitudes and behaviour, even when the duration of a science communication activity is short. Furthermore, they expect that these changes occur within a short time whereas little is known about their persistence into the future. Some strategies have been developed in order to go beyond the analysis of effects produced in the short term. Neresini and Pellegrini [2008] have proposed taking into account effects generated by successive instances of participation in science communication activities of the same kind, as well as the employment of follow-up questionnaires to determine whether changes observed in the short term are sufficiently consolidated for long term observation.

Evaluation is always complex and involves methodological and epistemological issues that go beyond the scope of the present paper. By discussing some of the challenges involved in evaluation we do not aim to arrive at an ideal method (which is most likely unreachable) but to foreground the limitations and advantages of different methods and the need to adopt methods that are appropriate to a given activity. Assessing the outcomes of science communication activities still has a long way to go and contributions from researchers and from the various agents acting in the area are much needed.

\section{Children's drawings as tools for assessment}

Research has shown that visual representations, such as children's drawings, are important resources to study symbolic meanings, perceptions and cognitive 
development [Barraza, 1999; Cherney et al., 2006; Cox, 2005; Kendrick and Mckay, 2004; Wright, 2007]. This has significant implications for fields like science education and science communication. The potential of children's drawings in aesthetic, educational and clinical terms has since long motivated multiple studies. It is generally accepted that children's illustrations are influenced by their society's dominant culture and by schooling, reflecting their social world, self and culture [Cherney et al., 2006]. Hence, children's drawings can be a means to assess their representational world (ibid.) and offer clues to observe how children's representations of one phenomena change over time according to new experiences.

For these reasons, and as many children enjoy drawing, their drawings are an easy-to-generate and useful tool for assessing their perceptions and knowledge. Drawings work as mirrors of children's feelings and thoughts and are a valuable alternative to answering questions or doing tests [Barraza, 1999]. Moreover, when compared with other methods, like interviews or focus groups, drawings are something that children do naturally, and in this sense are not influenced by interactions with an adult (posing questions or engaging in conversation), therefore minimizing the "noise" of the researcher's intervention and offering the child an active and empowering role [Mitchell, 2006].

The use of drawings for assessment of knowledge acquisition, perceptions and understanding of a specific scientific issue is not new. Cherney et al. [2006] and Mitchell [2006] pointed out the importance of drawings for understanding children's cognitive development and implications in many fields. Drawings have also been used as a strategy to access young children's views and experiences of school [Einarsdottir, Dockett and Perry, 2009]. Barraza [1999] used drawings in the assessment of children's environmental perceptions, and explored the combination between their ability to draw, knowledge and visual perception, as vital elements "for the development of the higher thinking processes and mental representations" (p. 61). In turn, Pion et al. [1997] used the draw-and-write technique as an evaluation tool regarding children's perceptions of skin cancer and showed its usefulness in providing information for health education programs. In Buldu's [2006] research, children's drawings were employed to study how their perceptions of science and scientists may influence attitudes towards science. Bryce and Blown [2013] and Dunlop [2000] studies also included children's drawings to analyze children's ideas about the Earth, the Sun and the Moon and to look for the source of some persistent misconceptions related to the conceptual models that young people use to theorize about these celestial objects.

As argued by Bucchi and Saracino [2016], images, including drawings, are essential in the communication of modern science both in academia and to various publics. The importance of images in this process has implications for science literacy and in the "discussion of public understanding of science at the international level" (p. 2). It is argued that "familiarity with science images could provide a relevant hook for science communication strategies, by anchoring more substantial information to already familiar images across different sectors of the general public" (p. 5).

The way children draw is a starting point for their visual literacy, since drawing is an activity that creates meaning and in which visual elements are used to share information, knowledge and ideas [Kress, 2003]. Visual signs are based on iconicity but also aim to create an impression of similarity [Sonesson, 1989 cited by 
Hopperstad, 2008]. However, children's drawings cannot, at this age, express or convey the complexity of the objects or scenes they represent. Instead, they record invariant features of the world as they perceive it [Gibson, 2014]. Moreover, at this stage of development, children's drawings are not reproductions, but "symbols" of real things [Hopperstad, 2008].

Arnheim [1997] noted that at an age when they easily distinguish one person from another and appreciate the smallest change in a familiar object, children's drawings are still highly undifferentiated. He suggested that one reason for this disparity may be in the nature and function of pictorial representation, as the image of an object depends on the standards of designers and on the purpose of their drawing. Differences are easily noted when comparing the perceived object and its representation, because the perception is not a faithful "photographic" record, but the seizure of global structural features (ibid.).

Drawing is a way of communicating that works as a visual reflection of the mind, and that expresses cultural significance more than the detail or materiality of the object [Barthes, 1964]. The individual creates images and representations based on objective and specific phenomena that others can recognize [Yañez, Chávez and de Sevilla, 2008]. Assessment experiments with children allow us to understand the importance of representing concepts, therefore highlighting the difference between recognition and imitation.

The study reported here aimed to infer the influence of a science communication activity in the perception that children in the first grade of elementary school education have of the world around and the phenomena they observe in it. More specifically, it aimed to identify potential changes in graphical representations of the Sun further to a non-formal activity carried out at school.

Several aspects were taken into account for choosing first grade children (ages six and seven). The fact that they had only recently entered the formal learning system removed, to some degree, the possibility of a pre-existing structured procedure on how to behave when confronted with an observation session such as the one that we organized. Also, their learning still took place mostly through recreational and leisure activities. They were at ease with a form of expression that is used both in recreational (non-formal) and school (formal) contexts and can be used without an implicit suggestion of any kind of assessment: the drawing. Furthermore, for children, drawing is an activity that creates meaning, with visuals being used to share information, knowledge and ideas [Kress, 2003] — in other words, a valuable instrument to assess the perception that children have of the world around.

\section{Activity description}

Our objective was to understand how a particular activity of science communication can impact on visual modes of perceiving the world. The targeted public were children from the first year of basic education from an urban school in Viseu, a medium-sized town in Portugal. All the children were of Portuguese nationality and no other ethnic group or origin was found. 
In May 2013, during a normal school day, eighteen children were invited to make a "free" drawing of the Sun, unaware of the purpose of the task. In June of the same year they were asked to draw it again, but this time after having attended an observation session of the Sun using a fully equipped telescope, accompanied by a brief individual explanation of the phenomenon they were about to observe. The promoter of the activity explained to them that they would observe the Sun through a suitably protected equipment. They were instructed on what precautions to take, in particular to never look directly to the Sun, and much less so through magnifiers, binoculars or telescopes not protected with proper equipment and managed by professionals. Then, two by two, they went up to the equipment: a telescope and a solarscope. As they watched, the facilitator asked them what they saw, explaining that they were watching the Sun and that the dots they were observing on its surface were areas that are less hot, called sunspots. The explanation was given in identical terms to everyone.

In the third stage, which occurred in January 2014, those children, then in the second grade of primary school education, were asked to draw the Sun once again. There was no suggestion or allusion to the activity of solar observation. The group of children remained unchanged throughout the study.

Data analysis and discussion

\section{Construction of indicators}

For the purpose of analysis, drawings were placed side by side and a list of measurable indicators was developed, which was the basis of the comparative analysis between different times. Three pairs of drawings (Figures 1 and 2) are presented below as examples. They were made by two children of different genders, before observing the Sun, afterwards and some months later.
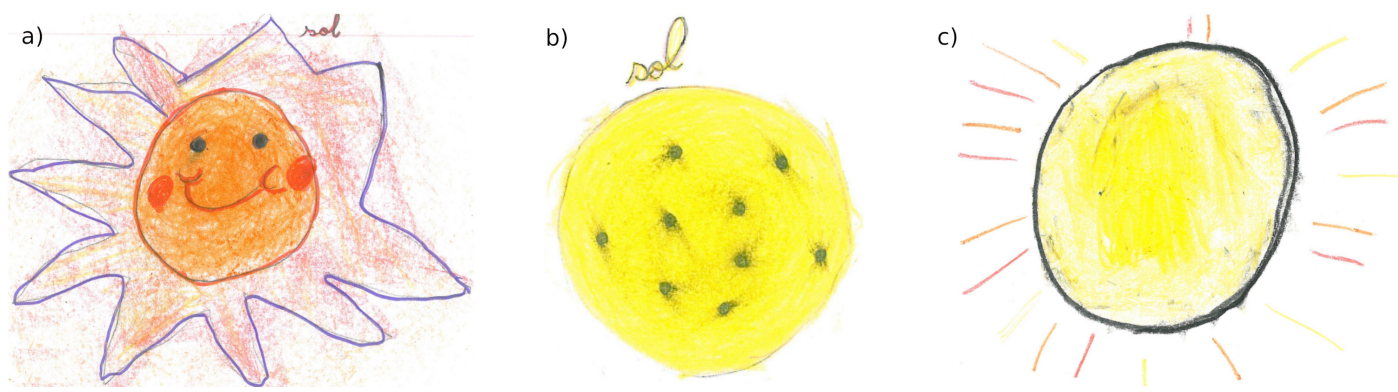

Figure 1. Drawings of the Sun made by Isabel (not her real name). a) Before observation session; b) afterwards; c) long after.

Differences between drawings in the three moments are remarkable. In the first moment, human features such as eyes, mouth, nose and even personality stand out, in a clear anthropomorphisation of the Sun. Daniel's drawing, for instance, represents an irreverent Sun, which talks and sticks its tongue out. In the second moment, the Sun is represented as having only one colour, yellow, and with the clear presence of sunspots. In the third moment, what emerges is the absence of anthropomorphic characteristics of the Sun and a significant visual reference to sunspots and solar rays (as in the second moment).

Table 1 presents the full list of indicators regarding the data collected for all the 18 children. The construction of indicators resulted from a systematic analysis of the 

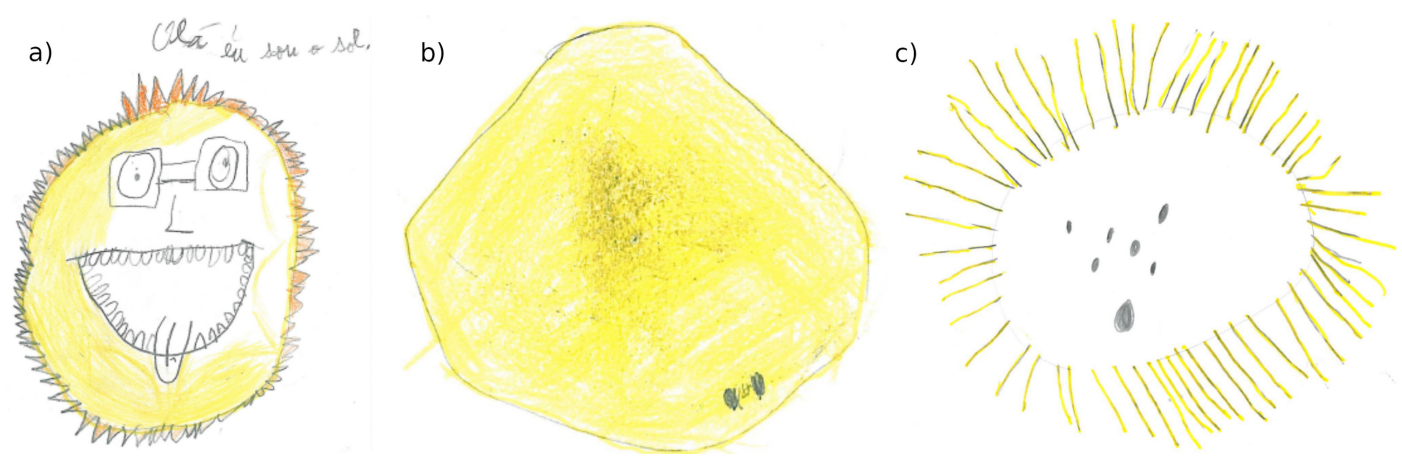

Figure 2. Drawings of the Sun made by Daniel (not his real name).

drawings. As the analysis expanded, new indicators arose to reflect what was found in the drawings. An example of the flexibility in creating indicators concerns the presence of sunspots in the second and third moments of the study. In order to record signals of a scientific outlook (with greater or lesser accuracy), we created specific indicators to map details in the representation of the Sun, such as the number of sunspots, their location (right on the edge, in the center or around the Sun), the distribution of sunspots (whether dispersed or concentrated in one place) and the size of sunspots (whether large, small or both) (see Table 1).

Successive analysis of children's drawings allowed us to map features and identify differences, seeking to understand various signification processes. Considering the indicators listed in Table 1, we found noticeable differences between the first and the second moments, and between the second and the third moments. The indicators where we encountered the largest changes were: the shape of the Sun, the colours used to represent it, the presence of sun rays, the presence of sunspots and the anthropomorphic characteristics of the Sun. A detailed analysis of the drawings made in each moment ensues, as well as a thorough longitudinal comparison.

\section{First moment: drawings made before the observation session}

The following features were identified in the first moment: in all drawings the Sun had the shape of an almost perfect circle; in most drawings we observed the presence of more than one colour (14 in 18); sun rays were present in all drawings; the Sun presented human features, namely talking, smiling, and had either more masculine or more feminine features (16 out of 18). The latter aspect is associated with the selection of colours, the shape and length of the solar rays, which were often similar to longer or shorter hair, and generally corresponded to the gender of the drawer. In some drawings the Sun appeared to have a personality and even a personal name. It is worth emphasizing that in this first moment, some children introduced speech bubbles in their drawings, giving the Sun the ability to speak: e.g. "Hello, I am the Sun"; "I am the Sun and my name is Popi!". Sunspots were found in none of the drawings.

Overall, what we found in the drawings is, in the terms of Roland Barthes [1964], a representation of the cultural significance of this astronomical object rather than its materiality. We find ourselves in the reproduction of the concept of "Sun", 
Table 1. Indicators considered in the interpretation of drawings of the Sun made in three stages by a total of 18 children.

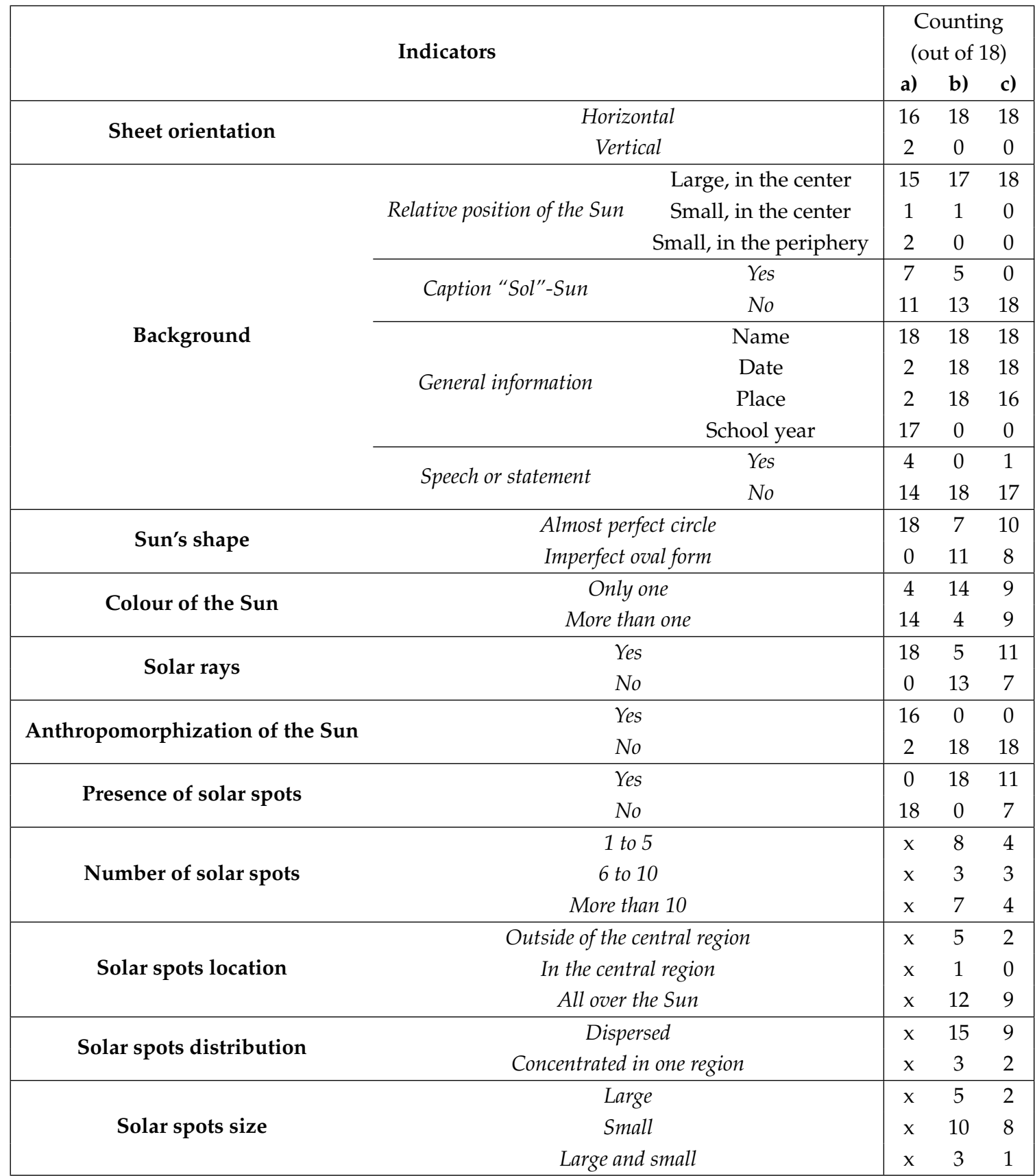

a) 1st moment: before observation; b) 2nd moment: after observing the Sun through a telescope;

c) 3rd moment: long after the observation.

with what it represents culturally, such as good disposition, colour and light. ${ }^{3}$ The images that children produced were informed by the totality of what they see and experience in their lives [Kendrick and Mckay, 2004], which includes a range of cultural and entertainment products, such as children story books, cartoons and advertising. Children often perceive the Sun as a living body with anthropomorphic features and habits [Villarroel and Villanueva, 2017; Kallery, 2011].

\footnotetext{
${ }^{3}$ Referring to the historical and cultural significance of the Sun, Durand and Godinho [1989] noted that it "means first of all light and supreme light" (p. 104).
} 
Furthermore, those images are also an expression of the designer her/himself: as mentioned above, in this study, representations of the Sun strongly relate to the image of their authors (irreverent, male or female, with or without glasses).

\section{Second moment: after the observation session}

The following changes were identified in children's graphical representations of the Sun after observing it through an optical instrument: the Sun's contour was predominantly represented as an oval shape (11 out of 18); in most drawings only one colour (yellow) was used to paint the Sun (14 out of 18); sun rays appeared in five drawings; the Sun lost its anthropomorphic characteristics; sunspots appeared in all drawings, in some cases, abundant and evenly distributed, in others, scarce and predominantly in a peripheral place in the Sun (the actual position of the spots in the specific day of the observation).

In this second phase, children rationalized the representation of the Sun, with the creative and cultural aspects of representation being clearly less present, making room for objectivity. An intention of reproducing the model, of creating similarity, was clear. When the drawings made in this second moment were compared to each other, we could see greater uniformity: the majority was mostly monochromatic, with a predominance of the yellow colour, all showed sunspots and human characteristics were absent; sunspots prevailed.

We are in the presence of a scientific image-type representation, as described by Joly [1996]. In their drawings, children display the ideas and the scientific concepts that they apprehended, shifting from everyday concepts to more scientific ones [Anderson, Ellis and Jones, 2014]. Scientific images seek to represent phenomena from an inquiring perspective. In this study, this kind of representation arose from the observation of a particular phenomenon - the presence of spots on the surface of the Sun - complemented by an explanation that enhanced a concrete observation, was attentive to detail, objective and situated. The use of technoscience, or, in other words, the use of technology applied to science, which in this case consisted in the employment of an optical telescope in order to enable a direct observation, appears to have been crucial to changes in perception and in the emergence of a 'scientific gaze'.

\section{Third moment: seven months later}

Without any reference being made to the day of the observational activity, seven months later children were asked to draw the Sun once again. The following characteristics were found in those drawings: predominance of the circular shape (10 out of 18); the Sun was represented with more than one colour in half of the drawings while the remainders had only one (yellow); solar rays had a distinct presence (11 out of 18); there was no reference whatsoever to anthropomorphic characteristics of the Sun; sunspots were depicted in 11 drawings. The number of spots was variable but they were predominantly located all over the Sun, distributed in a scattered way, and usually looking very small.

There were two main kinds of drawings, the difference residing in the presence or absence of sunspots. The seven drawings that had no sunspots were very similar to 
each other: circular shape of the Sun, yellow as the predominant colour and six of the drawings featured sun rays. The drawings with sunspots, if compared among themselves, exhibited greater diversity in terms of the presence or not, of sun rays; the location and distribution of the spots; or the choice of form and colour, despite yellow being predominant.

When the drawings were compared with each other, a variety of shapes and colours arose, reflecting an increased use of creativity and imagination and a smaller concern with similarity and accuracy regarding the object (the Sun). Nevertheless, in this third moment, the drawings included (some of) the knowledge that the children had acquired about the Sun. Although there had been no reference by the teacher or others to the activity of solar observation, the information obtained in that session was referenced in most drawings.

\section{Comparative analysis}

During this journey, highly significant changes occurred in the way children represented the Sun. They provide clues to better understand the aftereffect of the observational activity on children's conceptions of the Sun. To that purpose, a comprehensive analysis of the three moments is required.

The drawings from the first moment present a large diversity, resulting from a personal concept of what each child associates with the object "Sun". This was reflected in anthropomorphic features that were assigned to the Sun and in its identification (alikeness) with the individual/designer. In contrast with the initial diversity, in the second moment, it is the similarity between the drawings that stands out, specifically the representation of sunspots - the only phenomenon really visible in the Sun. Finally, in the third moment, we find a combination, a merging of the characteristics of the previous moments.

Several questions arise from this analysis: why is there more diversity in drawings in the first moment and why do we find a huge variety of colours? In the second moment, do the drawings represent the Sun or a specific phenomenon of the Sun (the sunspots)? Why are sun rays present in the first moment and become less prominent in the second only to reappear later on? Why has the circular shape of the Sun changed throughout the three moments?

The diversity found in the early drawings brings us to the question of iconicity, cited in the previous section. What children represented is the meaning they attribute to the Sun, which was projected in the drawing that they made. In Communication Sciences terms, drawings are signs and signs are resources that individuals use and adapt to construct meaning [Jewitt et al., 2001]. We can infer that the children built their own, individualized meaning, mirroring, in the graphical representation, their own ideas and assigning a meaning to the Sun that reflected themselves and their own (physical) image, hence the diversity and creativity observed. This explains the freedom in the use of multiple colours and the level of detail, an expression of the authors themselves.

In the second moment, drawings prominently expressed what was perceived of the observed phenomenon, specially the sunspots. Interpretation is a process that 
involves understanding and explanation. As an interpretation of what was observed, each drawing reveals an understanding of the phenomenon, on one hand, but it also integrates an effort of transmission (of information) to others, on the other hand. Thus, the attempt at similarity with the object represented takes precedence over imagination.

In the third moment, we found compositions with (some of the) features of drawings from the previous moments. One of the elements that deserves careful analysis are solar rays, which were prominently present initially, then disappeared almost entirely and reappeared in this last moment, although less exuberantly. The function seemingly assigned to solar rays varies: in the first images they appear as "hair" in anthropomorphic figures of the Sun, they loose prominence in the second moment, and come back in the final moment as an expression of the daily observation of the Sun, whose rays gain visibility by crossing the Earth's atmosphere. There is an integration of information resulting from daily observation with the one from the observation session. Some drawings combine both types of information with equal prominence.

The question of form is equally interesting. In the first drawings, the Sun appeared as rather circular, often to represent a face, but lost its perfect geometry in the second moment, perhaps because the focus was primarily on representing the sunspots. The tendency for a circular shape reappeared in the third moment. Then all the drawings that had solar rays were circular and all those that were not circular had no sun rays. We looked further at the relation between sun rays, shape and sunspots and found that in all the drawings where the Sun was not circular it had spots. This suggests that the Sun was not circular because of the focus on representing sunspots, thus confirming what we have already advanced.

Regarding colour, we observed gradual changes, starting with a wide variety, followed by a prevalence of yellow and ending with the convergence of dichromatic representations (yellow and orange). This development further points to the recovery of the creative component as a complement of the representational one in children's drawings.

Some of the changes observed along the three moments could be related to children's natural and expected cognitive development. However, the analysis of drawings of older children (nine and ten years old) rules this out, since they present highly similar features to those encountered in first graders before the observation session (see Table 2). In fact, drawings made by fourth graders under the same conditions of the first moment of the study for the first graders present the same general attributes as those made by first graders at that moment. In some cases, the only distinct feature is the increased complexity of the anthropomorphic representation of the characteristics of the Sun. This indicates that there is a considerable difference in the representation of the Sun between those who have attended the observation session and those who have not. Even as the years advance (as was the case of the second moment of the study with first grade children), those who have observed the Sun can recall the image of the Sun as a real object that they have seen through a telescope. Their perception of the object Sun was altered and it is different from those who have not experienced the activity, as Table 2 indicates. 
Table 2. Indicators considered in the interpretation of drawings of the Sun made before an observation session, for a total of 22 children of the fourth grade. No further study was conducted with these children.

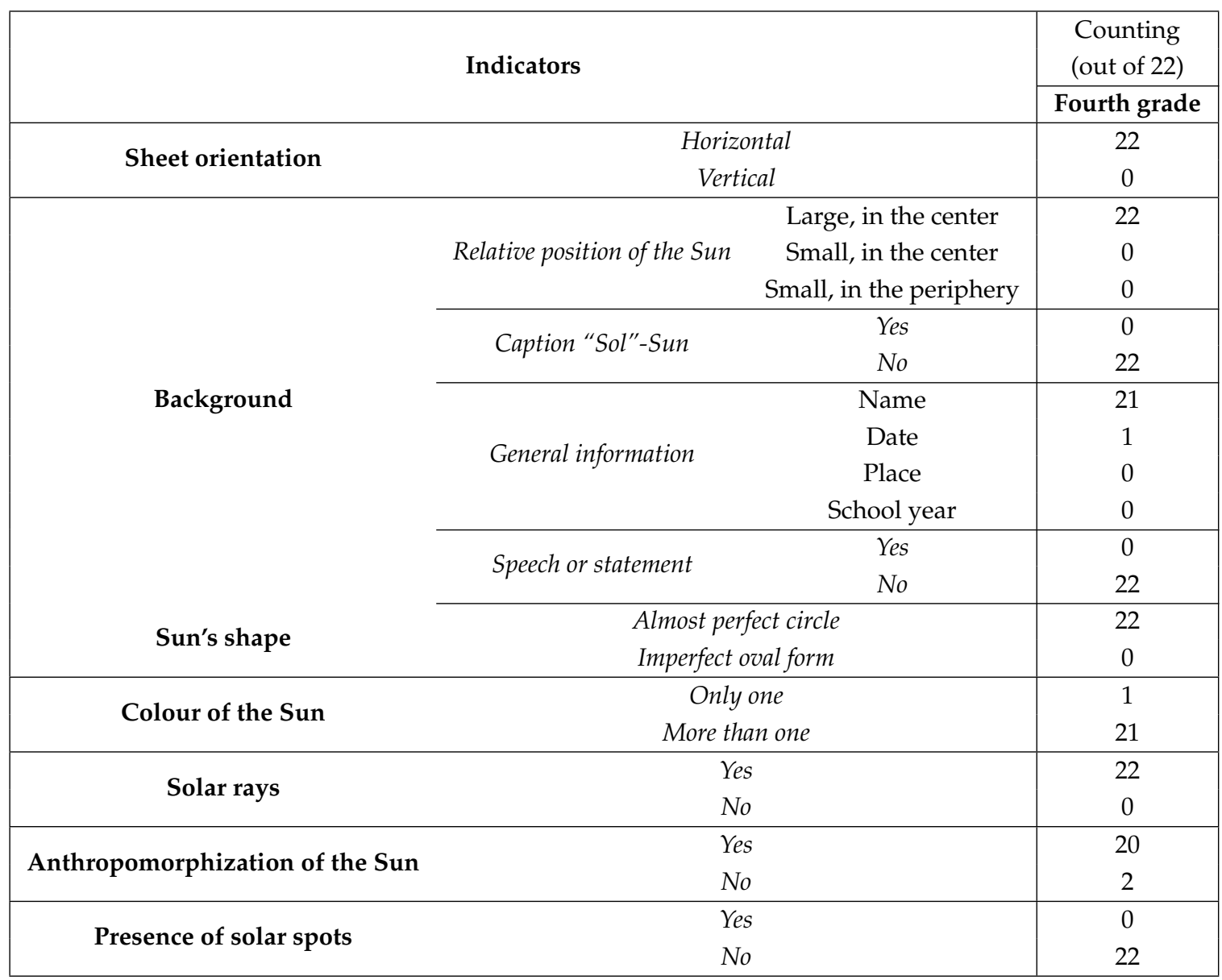

Based on a systematic and longitudinal analysis of children's drawings of the Sun, as well as on comparison with those of a different group of children, we may conclude that the science communication activity reported above produced changes in young children that have persisted in time.

Research suggests that images are of central importance in the communication of science and to enhance science literacy. In addition, they can be useful to infer changes in one's perceptions of a scientific issue. Children's drawings can be used as research data that allow for a rich analysis. They integrate physical, social and cultural aspects of the environment in which the child is inserted. In drawing, the child projects a meaning onto reality and produces an interpretation, a creative construction of possible meaning [Yañez, Chávez and de Sevilla, 2008], allowing us to identify, analyse and relate the symbolic elements used, and understand the sources that nourish that system of signification.

Throughout this study the Sun has evolved from an intangible object that, in the field of subjectivity, was assigned various symbolic meanings, to an observable object with characteristics of its own (rather than conferred by something external to it). This new facet of the Sun was enduring and yet did not usurp the previous 
"creative" version, as shown by children's recovery of a certain degree of freedom in the use of colour and the increasing diversity of representations in the last stage of our research design.

An integrative image, using two different sources of observational information, was formed: the information gathered by indirect everyday observation - the sun rays; and the information accessed by direct observation (through optical instruments) - the sunspots. The initial image of the Sun was thus challenged by new possibilities originating in scientific observation. This radically transformed the process of mental and graphical representation of the Sun. The object that once needed no observational information started to require it, thus becoming a physical object rather than a symbolic one.

The information given by each drawing shows how different forms of interaction - visual, actional and verbal - were combined to make meaning based on an observational astronomy activity. Although the outcome of the session was not the same for each child, the possibility to choose between different forms of representation is in itself of value: their range of options was increased. Their future personal experiences will determine whether to extrapolate this experience to an intrinsic way of evaluating the world around them or not.

To conclude, three contributions of the current study can be highlighted. Firstly, a greater understanding of the representations of the natural world elaborated by younger children, namely of the astronomical object Sun, will allow for identifying misconceptions and other alternative conceptions, and the sources they originate from. Understanding how early these misconceptions arise and how they originate is useful to look for strategies to overcome them at the most appropriate stage of children's development either in formal or in informal settings [Dunlop, 2000; Lelliott and Rollnick, 2010; Stocklmayer, Gore and Bryant, 2001]. Many of the misconceptions related to astronomy (e.g day and night, seasons, Moon phases, and the concepts of size and distance) are visually counter-intuitive. The Sun is an important piece in the elaboration of these conceptions (it is enough to consider, for example, the apparent movement of the Sun in the sky).

The second main contribution of this study is to suggest that learning to make scientific observations may further children's literacy. In astronomy and in other areas, taking observational and visual literacy seriously is valuable in building a solid foundation for scientific literacy [Kress, 2003; Bucchi and Saracino, 2016]. Images are strong supports in representations and conceptions of science, especially for the younger, so they deserve a special attention, which does not always happen.

Thirdly, the use of child-centered evaluation methods (such as drawings), allows for accessing children's starting point in the construction of their literacy using different modes of representation (besides reading and writing). This indicates that it is important to go beyond established evaluation methodologies in science communication activities for those audiences [Cox, 2005; Kendrick and Mckay, 2004; Mitchell, 2006; Wright, 2007].

In terms of the practice of science communication, three simple but crucial points can be made about science communication assessment activities in connection with this research. Firstly, one or more goals must be well defined: for instance, to enrich 
people's understanding of observational phenomena from a scientific point of view, as in the case presented here. Secondly, assessing changes in the public's perceptions is a very important step to validate and improve the activity itself. And finally, feedback-based design of science communication activities must be carried out. Understanding how socially and culturally-based meanings may shape the views that various publics hold of scientific phenomena should be a key aim and be taken into account throughout the different stages of science communication activities.

Acknowledgments

References
Sara Anjos holds a Ph.D. grant (SFRH/BD/123276/2016) co-financed by FCT/FSE/MCTES through national funds.

Anderson, J. L., Ellis, J. P. and Jones, A. M. (2014). ‘Understanding early elementary children's conceptual knowledge of plant structure and function through drawings'. CBE - Life Sciences Education 13 (3), pp. 375-386. https://doi.org/10.1187/cbe.13-12-0230.

Arnheim, R. (1997). Arte e percepção visual. Editorial Presença.

Baity, E. C., Aveni, A. F., Berger, R., Bretternitz, D. A., Clark, G. A., Dow, J. W., Kelley, D. H., Klejn, L. S., Loops, H. H. E., Muller, R., Pittioni, R., Pleslova-Stikova, E., Pohorecky, Z. S., Reyman, J. E., Roy, S. B., Smiley, C. H., Snow, D. R., Swauger, J. L. and Vermeersch, P. M. (1973). 'Archaeoastronomy and ethnoastronomy so far [and comments and reply]'. Current Anthropology 14 (4), pp. 389-449. https://doi.org/10.1086/201351.

Barraza, L. (1999). 'Children's drawings about the environment'. Environmental Education Research 5 (1), pp. 49-66. https://doi.org/10.1080/1350462990050103.

Barthes, R. (1964). 'Rhétorique de l'image'. Communications 4 (1), pp. 40-51. https://doi.org/10.3406/comm.1964.1027.

Bjornavold, J. (2000). Making learning visible: identification, assessment and recognition of non-formal learning in Europe.

Bryce, T. G. K. and Blown, E. J. (2013). 'Children's concepts of the shape and size of the earth, sun and moon'. International Journal of Science Education 35 (3), pp. 388-446. https://doi.org/10.1080/09500693.2012.750432.

Bucchi, M. and Saracino, B. (2016). "Visual Science Literacy”: images and public understanding of science in the digital age'. Science Communication 38 (6), pp. 812-819. https://doi.org/10.1177/1075547016677833.

Buldu, M. (2006). 'Young children's perceptionsof scientists: a preliminary study'. Educational Research 48 (1), pp. 121-132. https://doi.org/10.1080/00131880500498602.

Burns, T. W., O'Connor, D. J. and Stocklmayer, S. M. (2003). 'Science Communication: A Contemporary Definition'. Public Understanding of Science 12 (2), pp. 183-202. https://doi.org/10.1177/09636625030122004.

Cherney, I. D., Seiwert, C. S., Dickey, T. M. and Flichtbeil, J. D. (2006). ‘Children's drawings: a mirror to their minds'. Educational Psychology 26 (1), pp. 127-142. https://doi.org/10.1080/01443410500344167.

Cox, S. (2005). 'Intention and meaning in young children's drawing'. International Journal of Art $\mathcal{E}$ Design Education 24 (2), pp. 115-125. https://doi.org/10.1111/j.1476-8070.2005.00432.x. 
Dunlop, J. (2000). 'How children observe the universe'. Publications of the Astronomical Society of Australia 17 (2), pp. 194-206.

https://doi.org/10.1071/as00194.

Durand, G. and Godinho, H. (1989). As estruturas antropológicas do imaginário: introdução à arquetipologia geral.

Einarsdottir, J., Dockett, S. and Perry, B. (2009). ‘Making meaning: children's perspectives expressed through drawings'. Early Child Development and Care 179 (2), pp. 217-232. https://doi .org/10.1080/03004430802666999.

Gibson, J. J. (2014). The ecological approach to visual perception: classic edition. Psychology Press.

Grand, A. and Sardo, A. M. (2017). 'What works in the field? Evaluating informal science events'. Frontiers in Communication 2. https://doi.org/10.3389/f comm.2017.00022.

Hackling, M., Goodrum, D. and Rennie, L. J. (2001). 'The state of science in Australian secondary schools'. Australian Science Teachers Journal 47 (4), pp. 6-17.

Hand, B., Lawrence, C. and Yore, L. D. (1999). 'A writing in science framework designed to enhance science literacy'. International Journal of Science Education 21 (10), pp. 1021-1035. https://doi .org/10.1080/095006999290165.

Hopperstad, M. H. (2008). 'How children make meaning through drawing and play'. Visual Communication 7 (1), pp. 77-96.

https://doi.org/10.1177/1470357207084866.

Jensen, E. (2015). 'Evaluating impact and quality of experience in the 21st century: using technology to narrow the gap between science communication research and practice'. JCOM 14 (03), C05. https://doi .org/10.22323/2.14030305.

Jewitt, C., Kress, G., Ogborn, J. and Tsatsarelis, C. (2001). ‘Exploring learning through visual, actional and linguistic communication: the multimodal environment of a science classroom'. Educational Review 53 (1), pp. 5-18. https://doi.org/10.1080/00131910123753.

Joly, M. (1996). Introdução à análise da imagem. Papirus editora.

Kallery, M. (2011). 'Astronomical concepts and events awareness for young children'. International Journal of Science Education 33 (3), pp. 341-369. https://doi.org/10.1080/09500690903469082.

Kendrick, M. and Mckay, R. (2004). 'Drawings as an alternative way of understanding young children's constructions of literacy'. Journal of Early Childhood Literacy 4 (1), pp. 109-128. https: //doi.org/10.1177/1468798404041458.

Koolstra, C. M. (2008). 'An example of a science communication evaluation study: Discovery07, a Dutch science party'. JCOM 07 (02), A03. https://doi.org/10.22323/2.07020203.

Kress, G. (2003). Literacy in the new media age. Psychology Press.

Lelliott, A. and Rollnick, M. (2010). 'Big ideas: a review of astronomy education research 1974-2008'. International Journal of Science Education 32 (13), pp. 1771-1799. https://doi .org/10.1080/09500690903214546.

Miller, J. D. and Pardo, R. (2000). 'Civic scientific literacy and attitude to science and technology: a comparative analysis of the European Union, the United States, Japan and Canada'. In: Between understanding and trust: the public, science and technology, pp. 131-156.

Mitchell, L. M. (2006). ‘Child-centered? Thinking critically about children's drawings as a visual research method'. Visual Anthropology Review 22 (1), pp. 60-73. https://doi.org/10.1525/var.2006.22.1.60. 
Neresini, F. and Pellegrini, G. (2008). 'Evaluating public communication of science and technology'. In: Handbook of Public Communication of Science and Technology. Ed. by M. Bucchi and B. Trench. London, U.K. and New York, U.S.A.: Routledge, pp. 237-251.

Pidgeon, N. F., Poortinga, W., Rowe, G., Horlick-Jones, T., Walls, J. and O'Riordan, T. (2005). 'Using surveys in public participation processes for risk decision making: the case of the 2003 British GM nation? Public debate'. Risk Analysis 25 (2), pp. 467-479. https://doi.org/10.1111/j.1539-6924.2005.00603.x.

Pion, I. A., Kopf, A. W., Hughes, B. R., Wetton, N. M., Collins, M. and Bishop, J. A. N. (1997). 'Teaching children about skin cancer: the draw-and-write technique as an evaluation tool'. Pediatric Dermatology 14 (1), pp. 6-12. https://doi.org/10.1111/j.1525-1470.1997.tb00418.x.

Price, C. A. and Lee, H.-S. (2013). 'Changes in participants' scientific attitudes and epistemological beliefs during an astronomical citizen science project'. Journal of Research in Science Teaching 50 (7), pp. 773-801. https://doi.org/10.1002/tea.21090.

Rennie, L. J. (2001). 'Communicating science through interactive science centres: a research perspective'. In: Science communication in theory and practice. Ed. by S. M. Stocklmayer, M. M. Gore and C. Bryant. Dordrecht, The Netherlands: Springer, pp. 107-121. https://doi .org/10.1007/978-94-010-0620-0_7.

Rosenberg, M., Russo, P., Bladon, G. and Christensen, L. L. (2014). 'Astronomy in everyday life'. Communicating Astronomy to the Public Journal 14, pp. 30-36.

Rowe, G. and Frewer, L. J. (2004). 'Evaluating Public-Participation Exercises: A Research Agenda'. Science, Technology \& Human Values 29 (4), pp. 512-556. https://doi.org/10.1177/0162243903259197.

- (2005). 'A Typology of Public Engagement Mechanisms'. Science, Technology $\mathcal{E}$ Human Values 30 (2), pp. 251-290. https://doi.org/10.1177/0162243904271724.

Sjøberg, S. and Schreiner, C. (2010). The ROSE project: an overview and key findings. URL: https: //roseproject. no/?p=63.

Snow, C. E., Dibner, K. A. and Committee on Science Literacy and Public Perception of Science, eds. (2016). Science Literacy: Concepts, Contexts, and Consequences. Washington, D.C., U.S.A.: National Academies Press. https://doi.org/10.17226/23595.

Steiner, G. and Vilar, E. R. (2008). Is science nearing its limits? Manchester, U.K.: Carcanet Press Ltd.

Stocklmayer, S. M., Gore, M. M. and Bryant, C., eds. (2001). Science Communication in Theory and Practice. Dordrecht, the Netherlands: Kluwer Academic Publishers. https://doi.org/10.1007/978-94-010-0620-0.

Villarroel, J. D. and Villanueva, X. (2017). 'A study regarding the representation of the sun in young children's spontaneous drawings'. Social Sciences 6 (3), p. 95. https://doi.org/10.3390/socsci6030095.

Wright, S. (2007). 'Young children's meaning-making through drawing and 'telling': analogies to filmic textual features'. Australasian Journal of Early Childhood 32 (4), pp. 37-48. URL: http: //hdl . handle . net/10497/16986.

Yañez, C. E. J., Chávez, R. M. and de Sevilla, U. (2008). 'La sociedad del futuro: una mirada a traves del dibujo infantil'. The society of the future: a view through children drawings. Perspectivas de la Comunicación 1 (2), pp. 7-16. 
Yore, L., Bisanz, G. L. and Hand, B. M. (2003). 'Examining the literacy component of science literacy: 25 years of language arts and science research'. International Journal of Science Education 25 (6), pp. 689-725.

https://doi.org/10.1080/09500690305018.

Authors

\section{How to cite}

(C) The Author(s). This article is licensed under the terms of the Creative Commons Attribution - NonCommercial - NoDerivativeWorks 4.0 License.

ISSN 1824-2049. Published by SISSA Medialab. jcom.sissa.it
Sara Anjos is a Ph.D. candidate jointly at the University of Minho and at the University of Leiden. Her research interests focus on Science-Technology-Society Studies, particularly on public engagement with astronomy. Holds a 4 years university degree in Astronomy, an MSc in Science Education and an MBA. She is an active member of several research groups in the Science, Communication, and Education intersection and was the Portuguese Language Office of Astronomy for Development (PLOAD-IAU) coordinator until 2017. E-mail: saraanjos@gmail.com.

Alexandre Aibéo is a lecturer at the Instituto Politécnico de Viseu, and a solar astrophysics researcher. He was the Portuguese FameLab competition's winner, in 2010. As an enthusiastic promoter of scientific culture for the wider public, he developed more than 250 activities. He is the author of two books of science for the public (in the Portuguese language): 90\% do Caro Leitor Foi Feito nas Estrelas. (2016) and Isto não é (Só) Matemática. (2012) (as a co-author). Holds an Astronomy Ph.D. E-mail: aaibeo@gmail.com.

Anabela Carvalho is a Senior Lecturer at the Department of Communication Sciences of the University of Minho, where she teaches Communication, Science and the Environment, International Communication and Political Communication. She is the Director of the PhD programme "Communication Studies: Technology, Culture and Society", funded by the Portuguese Agency for the Science FCT. Her research focuses on various forms of environment, science and political communication with a particular emphasis on mediations of climate change, as well as connections to public engagement. E-mail: carvalho@ics.uminho.pt.

Anjos, S. Aibéo, A. and Carvalho, A. (2019). 'Observing and drawing the Sun: research-based insights to assess science communication practices aimed at children'. JCOM 18 (04), A03. https:/ / doi.org/10.22323/2.18040203. 